\title{
Modeling and Simulation of Milling Force of New Type Ball-nose End Mill
}

\author{
Shuai Li \\ College of Mechanical \& Electrical Engineering, \\ Zaozhuang University Shandong province, 277160; \\ lishuai66@163.com
}

Keywords: Ball-nose end mill; Inclined cutting; Milling force; Discretization; Modeling

\begin{abstract}
Ball-nose end mill is an essential tool for 3D hook face machining. It is extensively applied in mold, automobile and other fields. The paper set the geometric model of ball-nose end mill as the research basis, conducted discretization for ball-nose end mill cutter, deemed each discrete unit as inclined cutting, and established a 3D milling force mode which is applicable to ball-nose end mill. The result of comparison with traditional orthogonal spiral rake surface ball-nose end mill indicates that the 3D average milling force of the new type ball-nose end mill cutter is smaller but with better cutting parameters.
\end{abstract}

\section{Introduction}

On account of the better adaptability on the free-form hook face of ball-nose end mill, the cutter center is contained on the offset-surface of processing hook face. The calculation of cutter location point is comparatively simple, and is applicable to the processing of various types of free hook faces [1]. Ball-nose end mill is an indispensable and essential cutter for automobile, aerospace and mold manufacturing. Since the cutter shape is quite complicated, the cutting conditions on the cutter head are harsh, the axial force imposed on the cutter is high, precise modeling can hardly be established for calculation of milling force and milling vibration. Therefore, researchers have paid great attention on the milling process simulation of ball-nose end mill.

Scholars at home and abroad have conducted a great amount of researches on cutting force generated during ball-nose end milling process, the structure and geometric profile of ball-nose end mill, dynamics model, milling surface topography, vibration, cutting heat and the optimal milling parameters under different milling conditions, and have acquired active achievements. Jain et. al. [2] calculated the cutting force based on the cutting data of 2D coordinate system, and established a cutting force model of ball-nose end mill. Feng[3,4] et. al developed a milling force simulation model for ball-nose end mill with eccentricity and inclination of milling force simulation model based on a similar milling cutter edge line equation and nonlinear partial milling force model in power function. Gyu Man Kin et. al. [5] proposed a method to predict the average cutting force based on the cutting force diagram. M. Milfelner et. al. [6] established a source equation for cutting force prediction by utilizing artificial intelligence technology and self-connection analog simulation. With the continuous researches on processing principle of ball-nose end mill and cutting characteristics, the development of ball-nose end mill processing technology has been significantly accelerated.

\section{Establishment of Ball Head Blade Curve}

In micro-geometric simulation, generally there are two presentation models of cutter geometrical shape [7]. The first method is the blade curve analytic expression provided by the cutter manufacturer thus to easily obtain the coordinate value of any blade point on the cutter; the second method is to present blade curve to polynomial fitting curve of discrete point sets. The paper adopted the second method while performing geometric description of virtual manufactured ball-nose end mill. An equation for ball-nose end mill blade was obtained through measuring the blade points and curve fitting. The point coordinates of the primary cutter of ball-nose end mill are 
originated from the simulation results of the research group. The data measured at the discretization blade points of ball head at the rotating coordinate system $O_{1} X_{1} Y_{1} Z_{1}$ of the cutter is as shown in Table 1:

Table 1 Geometrical parameters of ball-nose end mill blade

\begin{tabular}{cccc}
\hline $\begin{array}{c}\text { Item } \\
\text { No. }\end{array}$ & $\begin{array}{c}\text { Phase } \\
\text { angle }(\beta)\end{array}$ & $\begin{array}{c}\text { Sphere center } \\
\text { angle }(\phi)\end{array}$ & $\begin{array}{c}\text { Front rake } \\
\text { angle }\left(\gamma_{0}\right)\end{array}$ \\
\hline 1 & 2.71 & 7.13 & 15.17 \\
2 & 5.35 & 13.46 & 21.07 \\
3 & 7.37 & 18.27 & 28.88 \\
4 & 9.34 & 22.87 & 29.97 \\
5 & 11.303 & 27.332 & 30.556 \\
6 & 13.27 & 31.75 & 30.85 \\
7 & 15.29 & 36.19 & 30.95 \\
8 & 17.39 & 40.70 & 30.91 \\
9 & 19.63 & 45.43 & 30.67 \\
10 & 22.09 & 50.54 & 30.26 \\
11 & 24.95 & 56.29 & 29.61 \\
12 & 28.62 & 63.53 & 28.48 \\
13 & 34.74 & 74.77 & 22.68 \\
14 & 37.02 & 78.74 & 18.64 \\
15 & 39.21 & 82.51 & 16.47 \\
\hline
\end{tabular}

$\beta$ is the phase angle of blade point in cutting tool rotating coordinate system $O_{1} X_{1} Y_{1} Z_{1} ; \varphi$ is the included angle between the connection line of blade point and sphere center, and the cutter axis. It is known as the sphere center angle; $r$ is the horizontal distance from a point on the cutter blade to the cutter axis; $Z$ is the vertical distance from one point on the cutter blade to tool nose, therefore, the expression of discrete blade point under the coordinate system $O_{1} X_{1} Y_{1} Z_{1}$ is:

$$
\left\{\begin{array}{l}
X_{1}=r \cos \beta \\
Y_{1}=r \sin \beta \\
Z_{1}=Z=R-\sqrt{R^{2}-r^{2}}
\end{array}\right.
$$

Where $r=R \sin \varphi, R$ is cutter diameter.

On account of the relationship between the position of discrete blade point in the cutting tool rotating coordinates $O_{1} X_{1} Y_{1} Z_{1}$, phase angle $\beta$ and sphere center angle $\varphi$, more coordinate values of discrete blade points shall be obtained to get precise fitting analytic expression of ball-nose end mill blade curve. For the measured data phase angle $\beta$ and sphere center angle $\varphi$, perform cubic spline interpolation with mathematical tool MATLAB thus to obtain more discrete blade point data. Such interpolation method is expressed with a cubic polynomial on each micro-segment. In addition, the first and second order differential coefficients are continuous thus to ensure smooth curve [8]. The cubic spline interpolation is as shown in Fig. 1. The relational expression between $\varphi$ and $\beta$ is obtained through second-order polynomial curve fitting of interpolation calculation results: 
$\sin \phi=-1.88 \sin ^{2} \beta+2.79 \sin \beta-0.013$

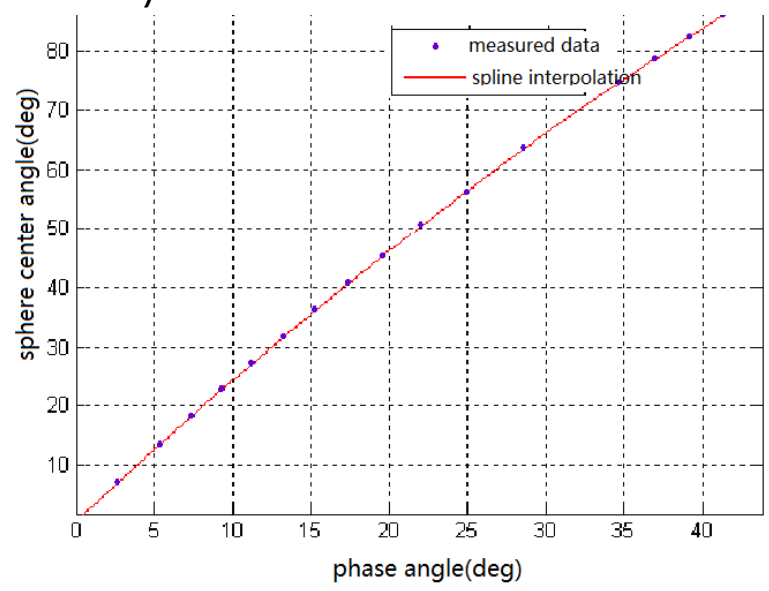

Figure 1. Cubic spline interpolation of phase angle $\beta$ and sphere center angle $\varphi$

From Eq.1 and Eq.2, the equation expressed by ball end mill blade curve fitting $\beta$ under cutting tool rotating coordinate system $O_{1} X_{1} Y_{1} Z_{1}$ is:

$$
\left\{\begin{array}{l}
X_{1}=R\left(-1.88 \sin ^{2} \beta \cos \beta+2.79 \sin \beta \cos \beta-0.013 \cos \beta\right) \\
Y_{1}=R\left(-1.88 \sin ^{3} \beta+2.79 \sin ^{2} \beta-0.013 \sin \beta\right) \\
Z_{1}=R-R \sqrt{1-\left(-1.88 \sin ^{2} \beta+2.79 \sin \beta-0.013\right)^{2}}
\end{array}\right.
$$

Discrete blade points and blade curve after fitting are as shown in Fig. 2.

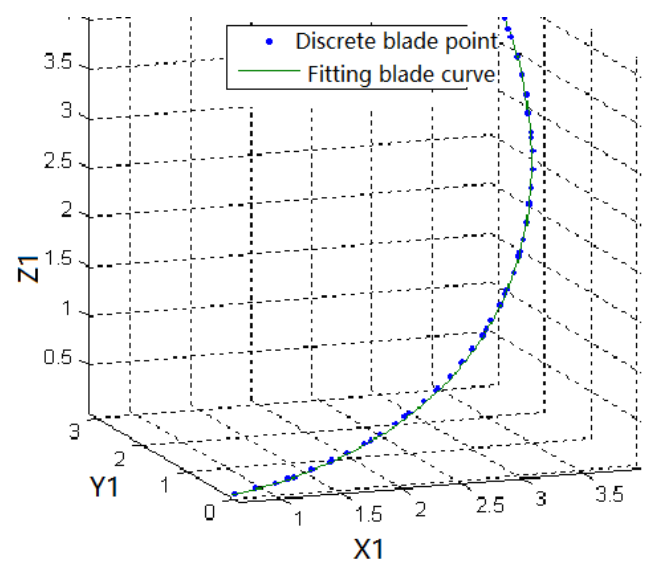

Figure 2. Discrete blade points and fitting blade curve

\section{Calculation of Instantaneous Cutting Force of Ball-nose End Mill}

The changes of ball-nose end mill blade shape were studied according to the milling force model of ball-nose end mill established, namely the impact of cutter geometric angle changes on milling force. The paper mainly analyzed the changes of instantaneous cutting force when the milling conditions of virtual manufactured ball-nose end mill and orthogonal helical rake face ball-nose end mill are the same.

If select the same tool radius $R=5.5 \mathrm{~mm}$, the total length $L=60 \mathrm{~mm}$, and the blade number is 2 . The cutter is made of hard alloy [9]. While at horizontal milling $\sigma_{b}=0.88 G P a$ carbon steel, the back engagement of the cutting edge $A_{p}=2 \mathrm{~mm}$, the rotational speed of primary axis $n=5500 \mathrm{rpm}$, and the feed per tooth $f_{z}=0.1 \mathrm{~mm} / z$, the instantaneous cutting force of virtual manufactured ball-nose end mill and orthogonal helical rake face ball-nose end mill are calculated by adopting MATLAB [10]. The results are as shown in Fig. 3, Fig. 4 and Fig. 5 respectively. 


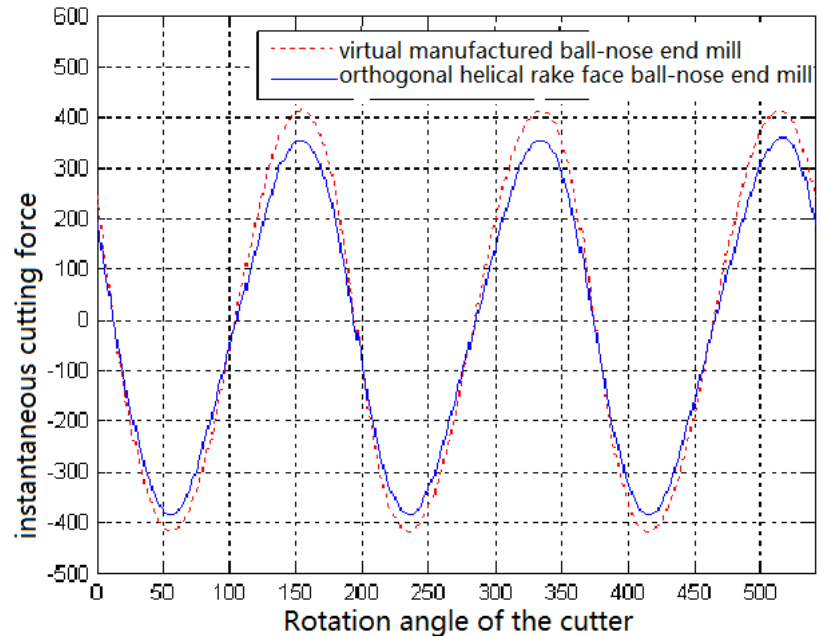

Figure 3. Instantaneous cutting force at direction $\mathrm{X}$ in case of

$$
A_{p}=2 \mathrm{~mm}, n=5500 \mathrm{rpm}, f_{\mathrm{Z}}=0.1 \mathrm{~mm} / \mathrm{z}
$$

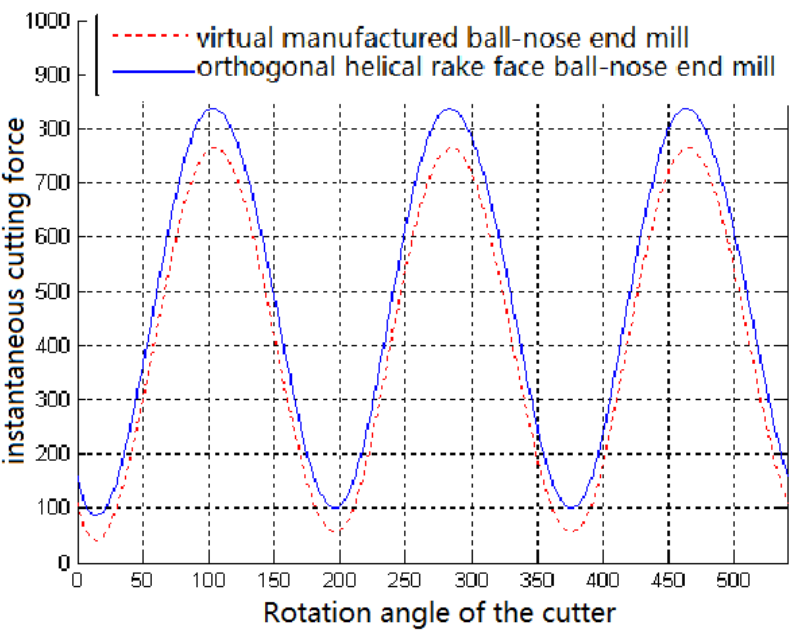

Figure 4. Instantaneous cutting force at direction $\mathrm{Y}$ in case of

$$
A_{p}=2 \mathrm{~mm}, n=5500 \mathrm{rpm}, f_{Z}=0.1 \mathrm{~mm} / \mathrm{z}
$$

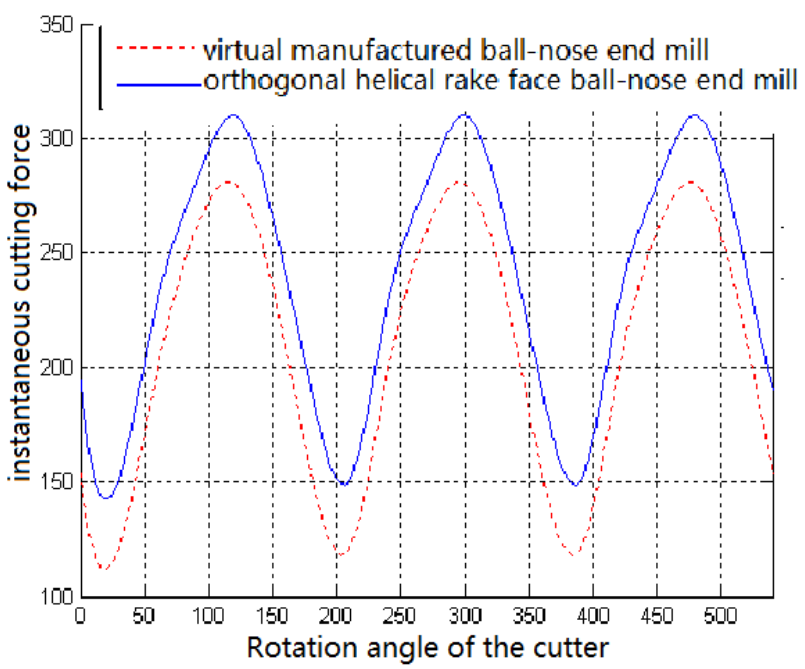

Figure 5. Instantaneous cutting force at direction $\mathrm{Z}$ in case of

$$
A_{p}=2 \mathrm{~mm}, n=5500 \mathrm{rpm}, f_{Z}=0.1 \mathrm{~mm} / \mathrm{z}
$$


As shown in Fig. 3, Fig. 4 and Fig. 5, under the same milling force, the milling force of virtual manufactured ball-nose end mill at the direction of X, $F_{x}$ is bigger than that of orthogonal helical rake face ball-nose end mill. And the milling forces of the virtual manufactured ball-nose end mill at the direction of $\mathrm{Y}$ and $\mathrm{Z}, F_{y}$ and $F_{z}$ shall be smaller than that of orthogonal helical rake face ball-nose end mill.

Through the analysis, it can be seen from back engagement of the cutting edge $A_{p}=2 \mathrm{~mm}$ of ball-nose end mill, the changing scope of the calculated phase angle $\beta$ is $0 \sim 30^{\circ}$. When the changing scope of the calculated phase angle $\beta$ is $0 \sim 30^{\circ}$, the front mounted toolbar rake angle $\gamma_{0}$ at virtual manufactured ball-nose end mill presents a changing tendency as small, big and small from ball tip to cylindrical part, namely the changing tendency of $5^{\circ} \rightarrow 31^{\circ} \rightarrow 27^{\circ}$; the changing tendency of tool cutting edge inclination $\lambda_{\mathrm{s}}$ is as small as $32^{\circ} \rightarrow 32.9^{\circ} \rightarrow 30^{\circ}$; the variation tendency of the two tool cutting edge angles $\mathrm{k}_{\gamma}$ are almost the same. And if the front mounted toolbar rake angle $\gamma_{0}$ of orthogonal helical rake face ball-nose end mill is smaller than that $\gamma_{0}$ of virtual manufactured ball-nose end mill, it presents a changing tendency from small to big from ball tip to cylindrical part, namely a changing tendency from $2.5^{\circ} \rightarrow 16.2^{\circ} \rightarrow 5.2^{\circ}$; the changing tendency of its tool cutting edge inclination is $4^{\circ} \rightarrow 27.5^{\circ}$.

It can be seen from metal cutting theory [11] that when the front rake angle of cutter increases, the cutter is comparatively sharp, and the total milling force will decrease; in case of increasing of tool cutting edge inclination, the milling force at the direction $F_{x}$ will increase correspondingly, and the milling force at the direction $F_{y}$ will decrease as well. Since the front rake angle of virtual manufactured ball-nose end mill is large, the milling force at the direction $F_{y}$ and $F_{z}$ will be small. And when the tool cutting edge inclination $\lambda_{\mathrm{s}}$ increases, the milling force at direction $F_{x}$ will increase correspondingly. Since the tool cutting edge inclination of virtual manufactured ball-nose end mill is bigger than that of orthogonal helical rake face ball-nose end mill, the milling force at the direction $F_{x}$ will bigger. The three-dimensional average milling force of the two is calculated as shown in Table 2.

Table 2. Three-dimensional average milling force

\begin{tabular}{ccc}
\hline $\begin{array}{c}\text { Force } \\
{[\mathrm{N}]}\end{array}$ & $\begin{array}{c}\text { virtual } \\
\text { ball-nose end mill }\end{array}$ & $\begin{array}{c}\text { manufactured } \\
\text { face ball-nose end mill }\end{array}$ \\
\hline$\overline{F_{X}}$ & 196 & 182 \\
$\overline{F_{Y}}$ & 421 & 446 \\
$\overline{F_{Z}}$ & 269 & 330 \\
\hline
\end{tabular}

It can be seen from the calculation results of Table 2 that the three-dimensional milling force of orthogonal helical rake face ball-nose end mill is comparatively uniform. The total milling force is smaller than that of orthogonal helical rake face ball-nose end mill. Therefore, it has better cutting performance.

\section{Conclusion}

The paper obtained a blade curve fitting formula by curve fitting of the discrete blade points on orthogonal helical rake face ball-nose end mill, and studied the cutting-tool angle of static coordinate system. Starting from the geometric model of ball-nose end mill, the paper conducted 
discretization for ball-nose end mill cutter, deemed each discrete unit as inclined cutting, and established a 3D milling force mode which is applicable to ball-nose end mill. Through analyzing the impact of the changes of tool geometry angles on instantaneous cutting force, it theoretically calculated the instantaneous cutting force of virtual manufactured ball-nose end mill and orthogonal helical rake face ball-nose end mill respectively. The result shows that comparing with orthogonal helical rake face ball-nose end mill; the new type ball-nose end mill has smaller three-dimensional milling force and better cutting performance.

\section{References}

[1] M.Q. Sun and Z.Y. Weng, Tool Engineering, Vol. 40 (2013) No.9,p.7.

[2] S.Jain and K.C.Yang, Proceedings of ASME Winter Annual Meeting ( San Francisco, 2011).p.55.

[3] H.Y. Feng and C.H. Meng, Cut Geometry Analysis and Model Verification. Int. J. Mach. Tools, Vol. 34(2014), p.711.

[4] H.Y. Feng and C.H. Meng, ASME Journal of Manufacturing Science and Engineering, Vol. 118(2006), p.461.

[5] Gyu Man Kin and Chong Nam Chu: Journal of Materials Processing Technology, Vol. 146(2004), p.303.

[6] M Milfelner, J Kopac and F Cus, U Zuperl, Journal of Materials Processing Technology, Vol. 164(2015), p.1554.

[7] T. Wang, Research on the Optimization of Mold Cavity NC Feed Rate Based on the Instantaneous Mold Cavity (MS. Dalian University of Technology, China 2015).

[8] X. Ai et. al, High Speed Machining Technology (National Defense Industry Press, China 2015).p.231.

[9] S.G. Xiao, Cutting Tool Materials and Their Rational Choice (China Machine Press, China 2014).p.56.

[10]W. Wei, Technical Manual of MATLAB Applied Mathematics Tool Kit (National Defence Industry Press, China 2016).p.124.

[11]Z.T. Cai, Theory of Metal Cutting (Tongji University Press, China 2015).p.46. 